\title{
DESENVOLVIMENTO DO TURISMO OU DESENVOLVIMENTO TURÍSTICO Reflexões com base em duas regiões atrasadas em São Paulo
}

\author{
Carlos Roberto Azzoni'
}

\begin{abstract}
RESUMO: O texto apresenta uma reflexão sobre as possibilidades do turismo constituir oelementodinamizador de economiasregionaisatrasadas. Estabelecese a diferenciação entre desenvolvimento do turismo na região (crescimento dessa atividade na região em relação à tendência observada no passado) e o desenvolvimento turístico da região (o desenvolvimento da atividade turística acarretando efeitos de encadeamento que levam à superação das condições de atraso econômico regional). Os casos das regiōes do Pontal do Paranapanema e do Vale do Ribeira, áreas economicamente atrasadas no Estado de São Paulo, são utilizados como exemplos para ilustrar a discussão. Conclui-se que a primeira delas apresenta apenas a possibilidade do desenvolvimento do turismo, enquanto as condiçz̃es existentes no Vale do Ribeira, respeitados os requisitos apresentados no texto, permitem acreditar no desenvolvimento turístico da região.
\end{abstract}

PALAVRAS-CHAVE: Turismo e desenvolvimento; desenvolvimento regional; desenvolvimento econômico; turismo em regiões atrasadas; efeitos multiplicadores; Pontal do Paranapanema; Vale do Ribeira; São Paulo; Brasil.

ABSTRACT: The paper provides a discussion of the necessary and sufficient conditions for a tourism-based process of economic development to take place in a lagged region. A distinction is made between development of the tourism in a region (increase in this activity above the regular trend) and development of a region through tourism (creation of multiplier effects that will activate the region's economy). The cases of two lagged regions in São Paulo State are considered as examples. The Pontal do Paranapanema region is considered to have conditions only for the development of its tourism sector; the Vale do Ribeira region, however, seems to have all the necessary conditions to face development through tourism.

\footnotetext{
1 Livre-Docente e Professor Associado da Faculdade de Economia, Administração e Contabilidade da Universidade de São Paulo.

End. para corresp.: Faculdade de Economia, Administração e Contabilidade da Universidade de São Paulo, Cidade Universitária “Armando de Salles Oliveira"- Caixa Postal 1 1.474-05508900 - São Paulo-SP - Brasil.
} 
KEY WORDS: Tourism and development; regional development; economic development; tourism in poor regions; linkage effects os tourism; Pontal do Paranapanema; Vale do Ribeira; Säo Paulo; Brasil.

\section{INTRODUÇÃO}

Regiões atrasadas chamam a atenção dos planejadores e cstudiosos, notada mente quando constituem bolsões de pobreza dentro de áreas relativamente ricas. Esse é o caso, por cxemplo, das regiões do Pontal do Paranapancma, no cxtremo oeste do Estado de São Paulo, c do Vale do Ribeira, posicionada ao sul da Capital, entre esta e a cidade de Curitiba. A primeira foi toda ocupada com atividades agrícolas nas décadas de 50 e 60 , estando no presente seus solos praticamente cxauridos. A segunda ainda não logrou ser ocupada de fato com atividades econômicas, constituindo uma espécic de oásis em um Estado cm que praticamente toda a terra já é cxplorada comercialmente.

A despeito de suas particularidades, guardam em comum a triste marca de serem as regiões mais pobres do Estado ${ }^{2}$. Isso poderia não ser um problema tão sério, em termos nacionais, se os niveis absolutos de pobreza nelas observados estivessem acima dos minimos preconizados pelas organizações envolvidas com os diferentes aspectos das condições de vida das populações. Ao contrário, além de estarem na rabeira da lista das regiões paulistas, as condições de vida nelas presentes são absolutamente inaceitáveis, por qualquer padrão que se queira lhes aplicar. São, portanto, regiões atrasadas que têm chamado a atenção das administrações estaduais ao longo do tempo, sem que estas pudessem romper tal situação de pobreza.

Evidentemente, além da pobreza na sua manifestação absoluta ser um problema sério per se, o posicionamento dessas regiões na vizinhança de áreas mais ricas, algumas das quais entre as mais prósperas do país, potencializa o problema. Assim é que as administrações que se sucedem no governo do Estado e mesmo na gestão das prefeituras envolvidas têm devotado atenção à tentativa de promover o rompimento das condições de atraso c carência dessas áreas, atć aqui com parcos resultados.

Muitos estudos e planos foram desenvolvidos ao longo do tempo a respeito desse assunt $0^{3}$, estando os problemas suficientemente diagnosticados. A questão principal é como propiciar as condições materiais e concretas para que essas regiões rompam com a dinâmica perversa de empobrecimento

\footnotetext{
2 Para uma caracterização das condiçōes socioeconômicas dessas regiōes e das demais áreas do Estado, consultar AZZONI (1993a).

3 Para um inventário recente desses estudos, consultar AZZONI (1991a e 1991b).
}

absoluto e relativo que as têm assolado. Nesse sentido, cumpre analisar as possibilidades do desenvolvimento autônomo de algumas atividades que possam gerar empregos e renda para as populações locais, criando assim as precondições necessárias a uma reversão da tendência sinistra que se vem observando nessas regiões.

Nesse sentido produz-se neste estudo uma reflexão sobre as possibilidades do turismo desempenhar esse importante papel. Para tanto, coloca-se como condição necessária que essa atividade tenha viabilidade econômica, especialmente quando observada pelo setor privado, conforme tratar-se-á no texto. Cumprindo-se essa condição, poder-se-á obter o desenvolvimento do turismo na região, ou seja, observa-se o crescimento dessa atividade com relação às tendências observadas no passado, por exemplo. Mas esse fato não implica que tais efeitos positivos serão suficientes para criar efeitos de encadeamento, que permitam reverter o processo de empobrecimento ou de estagnação que está por trás da situação de atraso regional. Caso o desenvolvimento do turismo na região possa acarretar os efeitos de encadeamento citados, obtém-se o desenvolvimento econômico da região através do turismo ou oque se pode melhor denominar por desenvolvimento turistico da região. A experiência das duas regiões enfocadas será considerada no contexto dessa dicotomia.

O trabalho está organizado em cinco partes, além desta introdução. No item 2 oferece-se uma brevíssima caracterização do ciclovicioso da pobreza nas duas regiões, destacando-se os pontos em comum e as especificidades. No item 3 especial atenção é devotada ao papel do turismo nos dois casos, procurando-se elencar aspectos favoráveis e desfavoráveis de cada uma das áreas. Em seguida, no item 4, discutem-se os possíveis impactos que as atividades turísticas poderiam causar na economia dessas regiões. Ao final são tecidas as considerações conclusivas do trabalho.

\section{CICLO VICIOSO DA POBREZA NAS REGIÕES DO PONTAL DO PARANAPANEMA E DO VALE DO RIBEIRA}

A literatura sobre desigualdades e desenvolvimento regionais é extrcmamente vasta, e não cabe aqui desenvolvê-la ${ }^{4}$. Para os objetivos deste texto, basta apontar duas correntes principais de pensamento: a que considera que o processo de desenvolvimento econômico traz consigo o crescimento das desigualdades entre as áreas de um país, e a que considera essas desigualda-

\footnotetext{
4 Para análises recent

consultar AZZONI (1993c) e SOUZA (1993). Além de adicionarem aspectos recentes ao debate, esses dois trabalhos apresentam um bom levantamento bibliográfico.
} 
des como "dores do crescimento", passando a diminuir após ter-se alcançado um determinado nível de renda. O debate entre essas versões continua ativo, sem que se tenham oferecido cvidências empíricas suficientes ou um convencimento teórico defínitivo.

Tendo-se em conta a própria experiência negativa das regiões destacadas para análise neste estudo, não parece adequado adotar-se o ponto de vista "convergente" (as desigualdades acabarão diminuindo com o desenvolvimento, com os níveis de renda de todas as regiões "convergindo" para a média nacional) para o trabalho. Por outro lado, se o objetivo é buscar instrumentos que possam fazer com que as regiões, aqui estudadas, possam superar os problemas econômicos e sociais que as afetam, tampouco parece adequado adotar-se o ponto de vista oposto, "divergente" (o desenvolvimento trará necessariamente a desigualdade), na sua forma pura, como apresentada por MYRDAL (1963). Para o objetivo específico de caracterizar o processo de empobrecimento relativo das duas regiões, é mais adequado adotar a variante exposta por HIRSCHMAN (1975). Esse autor, a despeito de apresentar entendimento do processo muito similar ao de Myrdal, entende serem concretas as possibilidades de revertê-lo através da ação governamental, enquanto Myrdal não vê positivamente essa alternativas

Assim sendo, o desenvolvimento das regiões consideradas neste estudo será analisado no contexto do modelo do ciclo vicioso da pobreza, conforme apresentado por Myrdal c Hirschman, mas com a interpretação deste segundo autor. A idéia básica está condensada na Figura 1, na qual são destacados quatro setores cconômicos: agricultura, agroindústria, indústria c turismo. E claro que poder-se-ia desagregar a análise em um número maior de setores, mas isso pouco acrescentaria ao entendimento do fenômeno. A seguir são analisados separadamente cada setor.

O desenvolvimento das atividades agrícolas encontra óbices de dificil superação nas duas regiões. Um ponto comum fundamental é o problema fundiário: apenas uma parcela muito pequena das terras passíveis de utilização agrícola tem sua posse claramente definida c registrada. Essa questão é crucial para a segurança quanto à realização de investimentos, melhoramentos e modernização, e para a tomada de empréstimos bancários (a terra não pode ser dada como garantia do financiamento). Qualquer solução de caráter definitivo para a agricultura das regiões deverá resolver esse complexo problema.

Embora crucial, o problema fundiário, infelizmente, não é o único. $\mathrm{O}$ pouco preparo técnico do agricultor típico das duas regiões é outro fator

5 AZZONI (1993c) apresenta com detalhes o pensamento desses autores. relevante de atraso. Esse despreparo se manifesta no emprego de técnicas de baixa produtividade, na escolha de produtos com poucas possibilidades comerciais e de lucratividade, no manuseio inadequado do solo, na cultura de produtos incompatíveis com a manutenção da qualidade do solo na região etc. Como conseqüência, registra-se uma baixíssima produtividade agrícola nessas áreas, que, somada aos problemas de baixo grau de profissionalização na comercialização, conferem às regiões um nível insuficiente de competitividade.

entre essa área c os principais centros consumidores é um fator adicional comprometedor da competitividade; já o Vale do Ribeira, por outrolado, não sofre desse problema, situando-se muito próximo deles. A qualidade do solo assume características distintas no Pontal e no Vale. No primeiro caso, tratase de solo arenoso, cujas melhores condições foram exauridas por um processo de ocupação desastroso nas décadas de 50 e 60 , onde o problema da erosão é de extrema gravidade; já o Vale do Ribeira apresenta topografia muito acidentada, dificultando em muito a ocupação de suas terras.

Esse processo acarreta o êxodo das populações rurais para as cidades da região e para regiões mais distantes. Como se sabe, a migração é seletiva, drenando da região as pessoas mais capazes e/ou mais jovens, ampliando o problema no futuro. A perda de peso populacional implica perda do peso eleitoral da região, comprometendo a capacidade de acionamento do poder público, estadual ou federal, no momento seguinte. Fecha-se assim o ciclo viçioso na agricultura.

A agroindústria, pela sua própria natureza, sofre com a existência de uma agricultura muito pobre na região. Além dos problemas culturais já citados, a falta de um mercado regional com porte suficiente para garantir uma escala mínima de produção, e a insuficiência de iniciativas e de capital privados são problemas adicionais. Em conseqüência, pode-se dizer que as regiões acabam vendendo produto in natura, com baixo valor adicionado, gerando assim poucos efeitos de encadeamento na economia regional.

No setor industrial, em que geralmente se concentram esforços nos planos de desenvolvimento regional, uma vezque esse setor é o que apresenta menores vínculos específicos com o território ${ }^{6}$, a situação é igualmente dificil. A ausência de infra-estrutura (energia elétrica, saneamento, centros urbanos dotados de capacidade de hospedar e atender com serviços urbanos a população adicional), alia-se à insuficiência de iniciativas empresariais locais, ausência de mercado regional, a grandedistância dos mercados (caso do Pontal do Paranapanema), para gerar um quadro de pouca atratividade pa injeções de capital de fora não são incentivadas pelo quadro existente.

6 Para uma análise desse tópico, consultar AZZONI (1993b) 
Quanto ao turismo, que será considerado com mais atenção adiante, o quadro não é distinto. Pobreza, falta de infra-estrutura, espírito empreendedor etc. afetam esse setor tanto quanto ou provavelmente mais do que os demais.

O quadro que se forma é típico das situações de regiões deprimidas em todo o mundo. Os efeitos negativos se sucedem, trazendo com eles efeitos negativos conseqüentes, que produzirão novos efeitos negativos na seqüência: materializa-se o ciclo vicioso da pobreza. O setor econômico não se desenvolve, as condições sociais se deterioram, os setores público, estadual e federal se afastam. Esse quadro está esquematicamente exposto na Figura 2 , onde se destaca o comportamento dos setores privado e público tendo em vista os problemas já citados e dando destaque aos óbices que representam o controle dos órgãos ambientais e os problemas fundiários.

\section{POSSIBILIDADES DO DESENVOLVIMENTO DE ATIVIDADES TURISTICAS (EM ESCALA CONSIDERÁVEL) NAS DUAS REGIÕES}

Na seção anterior discutiram-se os entraves que limitam o desenvolvimento do setor turístico nas duas regiões em análise. Cabe nesta parte do trabalho explorar em maior detalhe esse tópico, adicionando o lado do potencial disponível nessas regiões, e o tipo de esforço que seria necessário fazer para que tal potencial venha a ser adequadamente explorado. Nesse particular, há de se considerar as especificidades das regiões no que tange ao potencial de interesse turístico, pelo que as análises serão realizadas separadamente.

\subsection{Turismo no Pontal do Paranapanema}

Documento da Secretaria Estadual deEsportes e Turismo do Estado de São Paulo caracteriza as condições existentes no Pontal do Paranapanema de forma suficiente para os objetivos deste trabalho (GOVERNO DOESTADO DE SÃO PAULO, s.d.). Segundo esse estudo, os principais fatores positivos ao desenvolvimento do turismo na região são: existência de malha viária com muito boas condições; presença de grande quantidade de rios e reservatórios navegáveise piscosos; belezas naturais inexploradas; disponibilidade de dois aeroportos com pistas pavimentadas, sendo um deles com operação de vôos regulares (Presidente Prudente); e gastronomia diferenciada. Pelo lado negativo, são citados: a deficiência da hotelaria, do transporte ferroviário e a escassez e baixa qualidade do artesanato e folclore.
A par de aspectos muito pouco definidos, como "gastronomia diferenciada" e "belezas naturais inexploradas", os demais fatores positivos citados são de limitado interesse para produzir o eventual deslocamento de um turista de fora da região. A rigor, o único aspecto citado que pode ter essa característica é o relacionado às atividades aquáticas, posto que a região é pródiga nesses recursos. Aqui situa-se talvez o único grande fator de atração de turistas para a região, embora o próprio estudo, no inventário que faz dos meios de hospedagem, eventos, serviçosde apoio ctc. coloque limitações para que esse potencial se realize.

Por tratar-se de área de ocupação relativamente recente e, pior, predatória, aliado ao fato de que sua topografia não apresenta acidentes naturais de interesse, pode-se dizer que o potencial de atração é limitado com exceção da área relacionada aos recursos hídricos. Com exclusão da capital regional, Presidente Prudente, a rede urbana da região é constituida por cidades pequenas, muito pobres, desprovidas de atrativos históricos/urbanísticos, sofrendo processo de decadência econômica e esvaziamento demográfico, ou seja, o "anticlímax" para o turista. Soma-se a csses fatores a grande extensão da região, que faz com que eventuais pontos de interesse turístico posicionem-se em forma de isolamento geográfico, impedindo a necessária complementaridade de atividades, o queacaba impedindo a criação de efeitos sinérgicos positivos no setor turístico.

Finalmente, o distanciamento dessa área dos principais centros emissores de turistas é o ponto de maior relevância para a constituição da demanda por turismo na região. Esse problema não seria tão importante, se as atrações disponiveis assumissem massa de interesse que levasse um tipo de turista mais qualificado ao deslocamento. A Amazônia e o Pantanal são muito mais distantes, mas exercem atração suficiente para turistas de todo o Brasil e do Exterior. Infelizmente, não é o caso da região, pclas razões já expostas. Assim, acaba restando para a área o turista de renda limitada e das suas imediações, o que, pelas condições econômicas das regiões vizinhas e densidade de riqueza, não caracteriza um volume de demanda que permita identificar o turismo como uma atividade que possa promover a redenção econômica dessa região.

\subsection{Turismo no Vale do Ribeira}

Do ponto de vista das possibilidades e do papel que o turismo poderia ter no desenvolvimento regional, a situação do Vale do Ribeira é muito distinta da situação do Pontal do Paranapanema. Começando com a posição geográfica da área, passando pelas atrações de interesse turístico que apresenta e, finalmente, pelas limitações impostas ao desenvolvimento de 
qualquer outro tipo de atividade na sua jurisdição, o turismo não é apenas viável na área, como também crucial para o seu desenvolvimento.

Quanto às possibilidades, a região conhecida como Vale do Ribeira caracteriza-se pela cobertura vegetal de uma parcela importante do seu território típica de Mata Atlântica, atualmente protegida por legislação federal e estadual. Além desse aspecto, as características geológicas da área dão lugar a formações específicas, como grutas e cavernas, que despertam especial interesse histórico e paisagístico. Além desses atrativos, a região também dispõe de zona litorânea, com interesse para atividades de veraneio e pesca, e de cidades históricas, com patrimônio arquitetônico de alto interesse.

Na realidade, o Vale do Ribeira é constituído por trêsambientes físicos diferenciados: a zona serrana, a planície litorânea e a faixa costeira, cada uma com suas atrações específicas e diferenciadas. No caso em questão, um ponto favorável é a relativa proximidade das diversas atrações, criando uma densidade que magnifica o interesse pela região. Essa diversidade, além do interesse da cada uma das áreas em si, constitui condição necessária à criação da necessária sinergia que pode transformar o turismo em atividade motriz da economia regional.

Na zona serrana, a atração da floresta nativa, os recursos cênicos, a existência de dezenas de grutas e cavernas e a presença, atual e futura, de extensos lagos alimentadores de usinas hidrelétricas favorecem a programação de excursões e safáris fotográficos à mata e às cavernas, a caminhada por trilhas com variados graus de dificuldade, a instalação de belvederes, pousadas e colônias de férias associadas à educação ambiental, pesca e prática de esportes aquáticos (nas represas), a descida por corredeiras etc.

A planície litorânea é cortada pela principal rodovia de acesso à região Sul do país, a BR-1167', e sedia suas principais cidades. Essa área, embora de interesse turístico mais limitado (exceto pelo que de histórico há em suas cidades), tem condições para sediar os equipamentos e os serviços gerais de apoio ao conjunto de atividades que compõem um complexo regional de turismo, como agências bancárias, de câmbio e de viagens, transportadoras turísticas, organizadoras de eventos, locadoras de veículos ede equipamentos esportivos, terminais de transporte rodoviário, ferroviário e aeroporto, serviços especializados e de comunicações, comércio de artesanato e de produtos da região etc

7 Rodovia Régis Bittencourt, hoje uma das mais perigosas do pais mas em processo - embora, lento - de duplicação.
A faixa costeira possui vários atrativos associados à presença do ma do foz do Rio Ribeira de Iguape, formando o complexo lagunar estuarino Iguape-Cananéia, com a presença de ilhas, formações serranas, praias, sítios arqueológicos, cidades históricas, acentuada piscosidade etc., o que favorece a instalação de marinas, clubes náuticos, de pesca e mergulho, a programação de eventos e competições esportivas, a implantação de complexos hoteleiros e resorts, a realização de passeios náuticos por escunas, a programação de excursões variadas associadas à educação ambiental etc.

Essa diversidade e potencialidade são magnificadas pela posição espacial relativa da área: em um raio de $200 \mathrm{~km}$, situa-se uma população próxima a 20 milhões de habitantes, com uma renda per capita das mais elevadas do país. Esse fato indica o potencial de mercado que a região apresenta. Atualmente, esse potencial não é explorado de forma adequada, por razões muito próximas às presentes no caso do Pontal do Paranapanema embora no Vale do Ribeira o turismo tenha um papel mais importante do que naquela região. Basicamente, apenas a zona costeira é explorada comercialmente, com atividades de pesca e veraneio, e, principalmente de segundaresidência. Uma outra atração conhecida e incipientemente explorada são as cavernas, destacando-se a Caverna do Diabo, como atração principal Todavia, o acesso e as precárias condições de infra-estrutura urbana na área impedem que essa importante alternativa de desenvolvimento econômico seja explorada em sua plenitude.

\subsection{Condições Básicas para o Desenvolvimento do Turismo no Vale do Ribeira}

Evidentemente, a existência de demanda potencial não é condição suficiente para o desenvolvimento da atividade turística na escala adequada para promover a superação das condições de atraso da região. Fosse assim, esse atraso hoje não existiria da forma trágica que se observa na área. Para queesse potencial se materialize, é necessário que investimentos sejamfeitos para transformar pontos de interesse em atrações turísticas com propósito de exploração comercial. Aqui se coloca a necessidade de um planejamento do turismo na área, de modo que se possa romper as barreiras que até aqui limitaram a materialização dessa manifesta potencialidade.

Qualquer planejamento do desenvolvimento da área deve levar em conta as condições materiais concretas da economia brasileira e das tendências mundiais em ação. O ponto de partida fundamental é o desenvolvimento, em nível nacional e internacional, do interesse pelo turismo ecológico. Esse ponto implica que a preservaçãoambiental deve ser a preocupação dominante de qualquer plano de ação, sob pena de se afetar a principal atração da 
região. Isso posto, toda e qualquer ação deve atentar para a necessidade de preservação das condições de biodiversidade e do desenvolvimento sustentável, levando à preservação e mesmo recuperação do meio ambiente.

Esse ponto é crucial para a discussão do desenvolvimento regional, uma vez que as necessárias (independentemente da sua complementaridade com o interesse turístico que promovem) restrições ambientais acabam resultando em óbices praticamente insuperáveis para o desenvolvimento de outras atividades econômicas na região, notadamente as agrícolas e agroindustriais. Considerando-se a particularidade da região no que concerne ao seu interesse ambiental, praticamente a atividade turística, desde que compatível - como pode e deve ser-com essa restrição, acaba sendo a única alternativa disponível para a área. Infelizmente, essa condição, mesmo associada à já enfatizada existência de demanda potencial, não garantem a sua materialização.

Um outro aspecto a ser considerado em qualquer ação que pretenda ter a dimensão suficiente para promover o setor turístico, a ponto de torná-lo o principal fator no desenvolvimento da região, é que a principal fonte de financiamento das atividades envolvidas terá de vir necessariamente do setor privado da economia; considerando apenas o lado prático do problema, admite-se que o poder público não dispõe, e certamente não disporá nas próximas décadas, de recursos em volume suficiente para desempenhar a tarefa que se apresenta.

Essa constatação endereça à discussão da lucratividade esperada que as atividades turísticas possam trazer para os investidores privados. Essa discussão é similar a que se pode desenvolver a respeito das possibilidades do setor público promover o desenvolvimento regional. Pode-se argumentar com o fracasso do poder público no passado para convencer sobre a impossibilidade do seu sucesso no futuro; igual argumento, todavia, pode-se aplicar ao insucesso do próprio setor privado no passado, ou seja, se as potencialidades para o setor privado são tão evidentes, por que razão esse não se faz presente na região com a quantidade e a qualidade necessárias?

Aqui se coloca a questão da parceria entre setor público e setor privado. Alguns dos principais elementos condicionantes estão efetivamente nas mãos do setor público, a quem cabe promover as condições necessárias para que o setor privado ocupe o seu papel de principal agente investidor e financiador do crescimento da região. A preparação de um planejamento estratégico para a região é condição fundamental para a criação da necessária sinergia. Nele, os pontos de estrangulamento devem ser identificados e soluções criativas devem ser apresentadas. Se recursos, como sempre, serão necessários, há que se saber como priorizar e programar sua inversão, tendo em vista o desenvolvimento do programa como um todo, e não visto como atividades isoladas. Havendo clareza a respeito dos resultados, na medida do possível, a arregimentação de recursos privados poderá ser uma possibilidade concreta.

Esse papel catalisador necessariamente pertence ao setor público. Mas não se pode e nem se deve esperar que a realização das atividades, principalmente aquelas que encontram melhor desenvolvimento pelo setor privado, sejam implementadas por órgãos govemamentais.

\section{IMPACTOS DAS ATIVIDADES TURISTICAS NAS ECONOMIAS REGIONAIS}

Nesta seção produz-se uma discussão a respeito dos impactos que o desenvolvimento de atividades turísticas pode trazer para as regiões. Evidentemente, não procurar-se-á quantificar esses impactos, mas apenas discorrer sobre a sua possível existência e dimensão ${ }^{8}$. Fundamentalmente, deve-se refletir sobre a magnitude e amplitude de um programa de desenvolvimento turístico para que o mesmo venha a promover o desenvolvimento econômico de uma região. Enfim, deve-se discutir as condições necessárias para que se tenha o seu desenvolvimento turístico.

A análise dos impactos espaciais de atividades econômicas vem ganhando espaço crescente na literatura', constituindo-se um aspecto relevante no julgamento da conveniência da implementação de programas de investimento. Esse tipo de instrumental poderia ser aplicado no caso do desenvolvimento de um programa turístico para essas regiões, todavia não é o interesse neste texto. O que se fará é apontar algumas condições para que tal programa possa ter sucesso, com base na literatura a respeito do assunto.

O primeiro ponto a ser considerado é o de que o programa deverá criar o efeito sinérgico necessário ao rompimento das condições inerciais preexistentes. Para tanto, sua dimensão e abrangência são aspectos fundamentais. Assim sendo, não produzirá resultados tanto o tratamento parcial a apenas um ou poucos aspectos (projeto ou subprogramas) isoladamente ou o tratamento abrangente sem a intensidade necessária em todos ou em alguns dos programas cruciais. Por exemplo, no Vale do Ribeira a atividade turística mais desenvolvida situa-se na região costeira. A ênfase apenas nessa área ou Setor poderá ampliar o fluxo de turistas nessa parte da região, mas dificilmente criará as condições para um movimento grande o suficiente para criar

\footnotetext{
8 Para um ensaio no sentido de quantificar o papel das atividades turisticas no desenvolvimento regional, consultar ROLIM (1991) e RABAHY (1990, especialmente o capítulo III).

9 Ver, por exemplo, NIJKAMP e van PELT (1989). Para uma aplicação ao caso brasileiro, consultar ABLAS, AZZONI \& COMUNE (1991).
} 
empregos e renda na região como um todo. Da mesma forma, tratamentos tímidos em todos os pontos ou áreas simultaneamente também não criarão a "massa" necessária para o rompimento da inércia sinistra na região.

Outro aspecto fundamental é que o tratamento, além de abrangente, deve observar condições de integralidade. O sucesso de um programa de desenvolvimento do turismo na região está em colocar a área como um produto turístico per se, em condições de concorrer com outras áreas turísticas já estabelecidas, como Amazônia, Pantanal, Foz do Iguaçu etc. Em outras palavras, o desenvolvimento das atividades turísticas com aquelas que lhes dão apoio e sustentação deverá ser integrado ${ }^{10}$. Para tanto, há que elencar e trabalhar todos os produtos turísticos da região globalmente, de modo a caracterizar um conjunto denso e diversificado que possa apresentar-se ao mercado turístico como uma alternativa a ser seriamente considerada. Além disso, há que identificar e dar solução a todos os aspectos relacionados à infraestrutura turística, evitando-se pontos de estrangulamento que contribuam para reduzir a exploração do potencial de determinadas atrações. Finalmente, há que se preocupar com a forma de divulgação e promoção da área, sem o que o sucesso pode ficar comprometido.

Tendo em vista as já abordadas dificuldades de financiamento por parte do poder público, especial atenção deverá ser dada ao aspecto da implementação. A clara definição dos invcstimentos necessários em cada programa, subprograma, projeto, área, subárea etc. é pontofundamental para a identificação adequada das instâncias e responsabilidades. Uma vez aclarado esse ponto, há que se ter uma estratégia altamente profissional de articulação de recursos, envolvendo formas inovadoras de acionamento de fontes nacionais e internacionais, governamentais e não-governamentais, com interesse ambiental ou mesmo apenas de lucro privado. Parcerias, joint ventures, concessões, autorizações, cessões, comodatos etc. devem ser modalidades exploradas em cada caso, visando ampliar o leque de recursos disponiveis. Da agilidade e criatividade nessa área dependerá o sucesso na implementação do programa.

Até estc ponto foram discutidas as condições para que o desenvolvimento das atividades turísticas na área tenha sucesso. Cumpre agora avançar para a consideração das possibilidades de que, uma vez alcançado esse sucesso setorial, o mesmo proporcione as condições de superação do atraso econômico da região. Nesse ponto há que se voltar a diferenciar as duas áreas sob consideração neste texto.

10 Sobre essa idėia, embora não aplicada especificamente ao turismo, consultar LEINBACH \& CROMLEY (1989).
Para o caso do Pontal do Paranapanema, tendo em vista os aspectos apontados no item 3.1, dificilmente seriam preenchidas as condições arroladas nesta seção. Pelas razões expostas, entende-se que o turismo no Pontal doParanapanema não deve constituir a mola propulsora do desenvolvimento regional, posto que não dispõe de potencial para tanto. Isso não quer dizer que não se deva realizar esforços para o desenvolvimento do turismo naárea, uma vez que todo efeito positivo é bem-vindo, notadamente em região tão carente. Mas, ainda que contando com a colaboração da renda gerada no turismo, a região necessariamente deverá contar com outras atividades para o rompimento do ciclo vicioso que a tem condenado à pobreza" ${ }^{11}$. Trata-se, pois, de esforços no sentido do desenvolvimento do turismo na região e não do desenvolvimento turístico da região.

Já a condição do Vale do Ribeira é distinta. Além dos aspectos apontados no item 3.2, que caracterizam claramente o potencial da área, há queconsiderar ainda outros aspectos. Tendo em vista as limitações ambientais impostas à utilização dos recursos naturais da região, praticamente não há alternativas viáveis de desenvolvimento de out ro tipo de atividade econômica em volume suficiente para superar as suas condições de extrema pobreza. Por outro lado, essa mesma preservação não só pode ser compativel com o desenvolvimento da atividade turística como é crucial para esse desenvolvimento, ou seja, o fator que é considerado como o principal entrave ao desenvolvimento da região - conjuntamente com os problemas fundiários ali presentes - é exatamente o que pode garantir a manutenção do interesse pela área por parte da demanda de turismo.

Além disso, pela diversidadee densidade de atrações, proximidade do grande mercado, condições de acesso etc., a área tem condições de experimentar um volume de movimento turístico capaz de gerar renda e emprego em magnitude suficiente para romper as condições de atraso até aqui observadas. Sendo assim, acredita-se que o Vale do Ribeira apresenta as condições para que se obtenha não só o desenvolvimento do turismo na região - o que também pode acontecer no Pontal do Paranapanema - mas, mais importante, o desenvolvimento turístico da região.

\section{CONSIDERAÇÕES FINAIS}

Neste trabalho procurou-se refletir sobre as possibilidades de que o desenvolvimento do turismo em uma região possa acarretar o desenvolvimento econômico da mesma. Nesse sentido, tomou-se como referência a

\footnotetext{
11 Plano em preparação na Secretaria de Planejamento e Gestão do Estado de São Paulo encaminha a discussão desse tema e propõe estratégia de atuação para a área.
} 
experiência concreta de duas regiões carentes do Estado de São Paulo, quais sejam, Pontal do Paranapanema e Vale do Ribeira. Foram apontadas, embora superficialmente, as circunstâncias que têm levado essas áreas a colocarem. se como das mais pobres do Estado e mesmo do País, e os pontos de interesse que possam apresentar para odesenvolvimento da atividade turística em seus territórios. Adicionalmente, expressaram-se algumas condições importantes para que se alcance o sucesso no desenvolvimento das atividades turísticas nessas áreas e, principalmente, para que esse sucesso possa resultar $\mathrm{cm}$ um processo de superação das condições de atraso econômico e social observadas.

Pela análise das condições presentes em cada uma das áreas, entre as quais o volume, a densidade e a diversidade das atrações turísticas, além da posição geográfica das mesmas, entendeu-se que, ainda que o desenvolvimento do turismo seja factível nas duas regiões, essa possibilidade é maior na região do Vale do Ribeira. Ademais, nessa área há possibilidades concretas para que o desenvolvimento do turismo possa criar condições para a superação do seu atraso econômico. Nos termos da dicotomia colocada no título deste trabalho, entende-se que no Vale Ribeira há condições para um desenvolvimento turistico da região, sendo o desenvolvimento do turismo uma condição necessária, mas não suficiente. Já no Pontal do Paranapanema, o máximo que se conseguiria seria o desenvolvimento do turismo na região.

\section{REFERÊNCIAS BIBLIOGRÁFICAS}

ABLAS, L. A. Q., AZZONI, C. R. \& COMUNE, A. E. 1991. Impactos sobre o mercado de trabalho e infra-estrutura da implantação de usina termoelétrica na região de Campinas-SP. In: Novas e velhas legitimidades na reestruturação do território. Anais do IV Encontro Nacional da ANPUR. Salvador: ANPUR, p. 185-99.

AZZONI, C. R. (coord.) 1991a. Pontal do Paranapanema. Inventário de estudos, problemas e programas. São Paulo: Secretaria de Planejamento e Gestão/Coordenadoria de Planejameno Regional, abr. (mimeo.)

1991b. Vale do Ribeira. Inventário de estudos, problemas e programas. São Paulo: Secretaria de Planejamento e Gestão / Coordenadoria de Planejamento Regional, jun. (mimeo.).

1993a. Como está São Paulo? As pessoas, a produção, os municipios, o meio ambiente. São Paulo: Governo do Estado de São Paulo / Secretaria de Planejamento e Gestão, Coordenadoria de Planejamento Regional.

. 1993b. Economia de São Paulo: ainda a locomotiva? São Paulo em Perspectiva, São Paulo, Fundação SEADE.

1993c. Equilibrio, progresso técnico e desigualdades regionais no processo de desenvolvimento econômico. Análise Econômica, Porto Alegre, UFRS, ano 11, mar.

GOVERNO DO ESTADO DE SÃO PAULO. Secretaria de Esportes e Turismo, Coordenação de Turismo. (s.d.) Desenvolvimento Turistico do Pontal (mimeo).

HIRSCHMAN, A. O. 1975. The strategy of economic develnpment. Yale University Press.
LEINBACH, T. R. \& CROMLEY, R. G. 1989. Modeling integrated development investments in rural areas: an Indonesian illustration. International Regional Science Review, v. 12, n. 2, p. 229-43.

MYRDAL, G. 1963. Economic theory and underdeveloped regions, London: Methuen.

NIJKAMP, P. \& PELT, M. van. 1989. Spatial impact analysis in developing countries: method and application. International regional science review, v. 12, n.2, p. 211-28.

RABAHY W. A. 1990. Planejamento do turismo: estudos econômicos e fundamentos econométricos. São Paulo: Ediçōes Loyola.

ROLIM, C. F. C. 1991. Foz do lguaçu: ensaio sobre a formação de um complexo turísticoexportador. In: Novas e Velhas Legitimidades na Reestruturação do Território. Anais do IV Encontro Nacional da ANPUR. Salvador: ANPUR, p. 175-84.

SOUZA, N. J. 1993. Desenvolvimento polarizado e desequilibrios regionais no Brasil. Análise Econômica, Porto Alegre, UFRS, ano 11, mar. 
Figura 1 - CICLO DA POBREZA
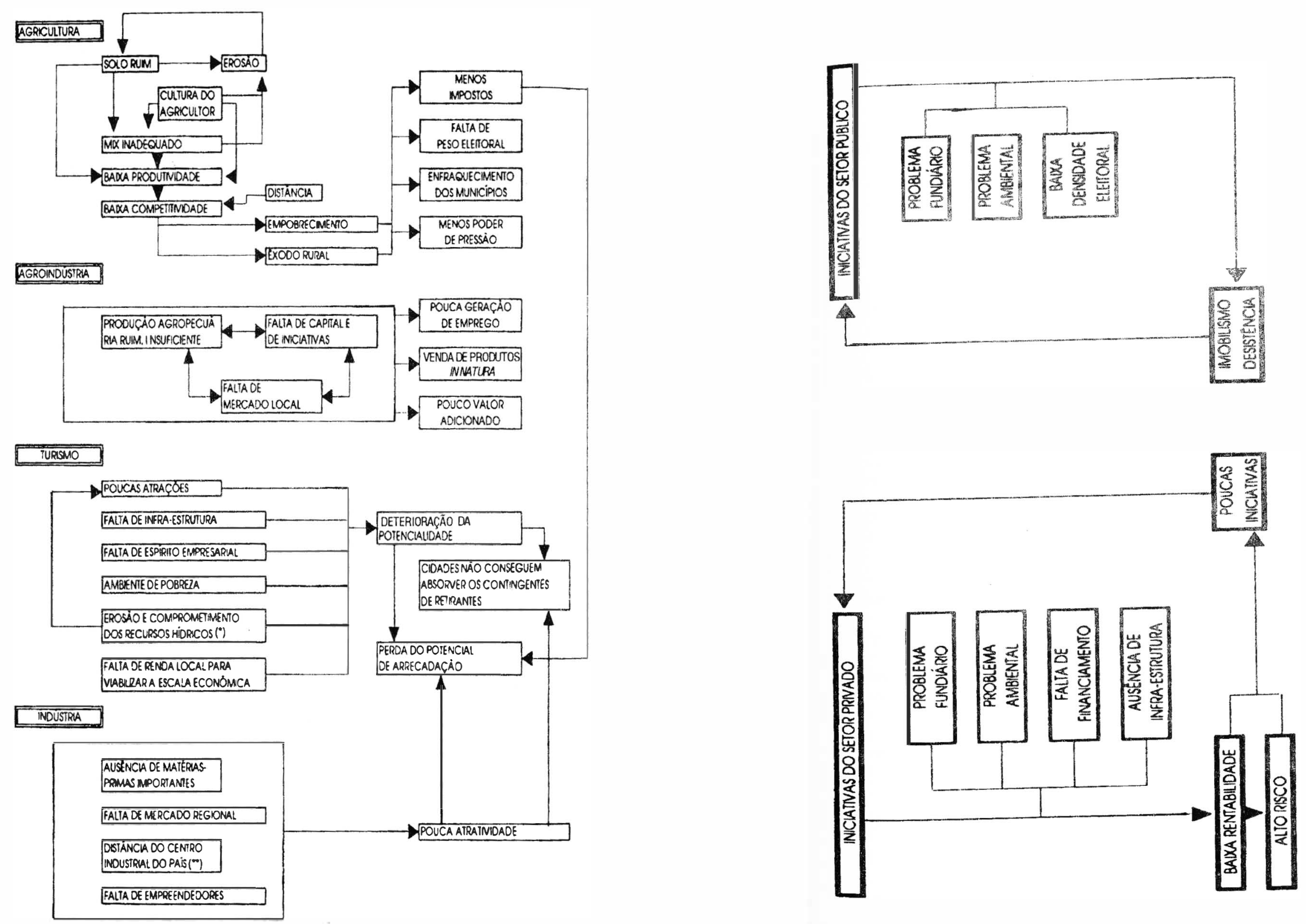